\title{
As eleições de 2018 no Estado do Rio de Janeiro: crônicas de um desastre político
}

Rafael Soares Gonçalves

\section{OpenEdition}

\section{Journals}

Edição electrónica

URL: http://journals.openedition.org/ideas/5443

DOI: 10.4000/ideas.5443

ISSN: 1950-5701

Editora

Institut des Amériques

Refêrencia eletrónica

Rafael Soares Gonçalves, « As eleições de 2018 no Estado do Rio de Janeiro: crônicas de um desastre político », IdeAs [Online], 13 | 2019, posto online em 01 março 2019, consultado o 02 maio 2019. URL http://journals.openedition.org/ideas/5443; DOI : 10.4000/ideas.5443

Este documento foi criado de forma automática no dia 2 Maio 2019

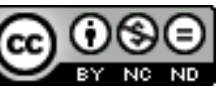

IdeAs - Idées d'Amériques est mis à disposition selon les termes de la licence Creative Commons Attribution - Pas d'Utilisation Commerciale - Pas de Modification 4.0 International. 


\title{
As eleições de 2018 no Estado de Rio de Janeiro: crônicas de um desastre político
}

\author{
Rafael Soares Gonçalves
}

1 Os resultados das eleições de 2018 trouxeram uma dura realidade para o País. Ele deu uma guinada para a extrema-direita com a eleição de Jair Bolsonaro como presidente da República. É preciso salientar que o bolsonarismo é maior do que a própria figura de Bolsonaro. 0 voto não era somente no pretenso carisma da figura insípida do novo chefe do executivo. Bolsonaro incarna uma ideia, uma nova direção política, que muitas vezes assume tons abertamente fascistas e que varreu o país nas últimas eleições. Seu partido, o PSL (Partido Social Liberal), que elegeu um deputado em 2014 e acabou a legislatura com oito, conseguiu eleger 52 deputados, configurando-se como o segundo partido do congresso. Elegeu, ainda, quatro senadores e três governadores.

Políticos de diferentes partidos se apoiaram no discurso de Bolsonaro para angariar votos. Essa maré conservadora atingiu todo o país, mas foi avassaladora sobretudo nos Estados do Sul, Sudeste e Centro Oeste. Um caso particular foi o Rio de Janeiro. Apesar de ser a principal base política da família Bolsonaro (com três filhos na política), eles nunca tinham sido eleitos para cargos majoritários. Bolsonaro cultivava uma base fiel de saudosistas da ditadura e simpatizantes de seu discurso extremista, que o elegeram por sete mandatos sucessivos à Câmara dos Deputados, mas nada poderia indicar que Bolsonaro tivesse ampla maioria em uma eleição presidencial.

O mais surpreendente, entretanto, foi a eleição do desconhecido Wilson Witzel para o Governo do Estado do Rio de Janeiro. Mesmo não tendo o apoio aberto do presidenciável Jair Bolsonaro, Witzel apareceu frequentemente na campanha eleitoral com candidatos a deputados do partido de Bolsonaro ${ }^{1}$. Flávio Bolsonaro, filho mais velho do atual presidente e eleito para o senado na última eleição, apoiou abertamente Witzel. No entanto, antes de 2018, o novo governador era um total desconhecido do público. Ex-juiz federal, entrou para política há alguns meses, justamente para se candidatar ao governo do Estado pelo PSC (Partido Social Cristão) ${ }^{2}$. Colecionou frases de efeito e propostas 
extremamente repressivas, sobretudo no âmbito da Segurança Pública, temática central de sua campanha política.

4 O crescimento de Witzel foi vertiginoso nos últimos dias de campanha. Não alcançava nem $1 \%$ das intenções de voto nas primeiras pesquisas eleitorais, chegou a $7 \%$ dos votos três dias antes das eleições. Alcançou $10 \%$ nas pesquisas da véspera do pleito e, surpreendentemente, atingiu $41 \%$ do eleitorado no primeiro turno e quase $60 \%$ dos votos no segundo turno, acabando com uma hegemonia do PMDB (MDB nos anos recentes) no Estado de quinze anos.

o presente artigo pretende compreender esse fenômeno, analisando o contexto político do Estado do Rio de Janeiro às vésperas das eleições, para depois centrar a reflexão na questão da segurança pública, pauta central da agenda política do governador eleito.

\section{A falência do Rio olímpico}

O modelo de desenvolvimento do Estado do Rio de Janeiro nos últimos anos se baseou, em grande parte, nos recursos do petróleo. O Estado é o maior produtor brasileiro e concentra grande parte de sua indústria de apoio. Outrossim, a cidade do Rio de Janeiro seguiu os passos de cidades como Barcelona, que buscaram sediar grandes eventos internacionais para impulsionar sua economia. Depois de ter tentado, sem sucesso, sediar os Jogos Olímpicos de 2004 e de 2012, a candidatura da cidade para os Jogos Panamericanos de 2007 foi finalmente aceita e se configurou como um marco na história recente da cidade. A partir dessa data e com a inédita confluência de interesses de todas as esferas de poder (União, Estado e município), a cidade sediou uma série de eventos internacionais, tendo como auge os jogos olímpicos de 2016.

7 A cidade do Rio de Janeiro atraiu os olhares do mundo nesse período e reforçou essa espécie de capitalidade ${ }^{3}$ resistente, que continua fazendo da cidade a vitrine do país, apesar do seu declínio político e econômico (Gonçalves R.S., 2016). A cidade virou um enorme canteiro de obras. Se, em relação à organização, os eventos foram relativamente um sucesso, as críticas quanto à sua preparação e seus pretensos legados foram extremamente duras (Magalhães A., 2013; Mascarenhas G., 2016; Vale J. do e Gonçalves R.S., 2018). As obras legitimaram o retorno de políticas de remoções de favelas e os investimentos em transportes não eram os mais adequados e estavam limitados ao tempo escasso de preparação da cidade e aos interesses dos empresários do ramo (Mendes A. e Legroux J., 2016).

8 No que tange mais especificamente à segurança pública, durante o período de preparação da cidade, os índices de violência urbana caíram bruscamente e o sucesso era dedicado às Unidades de Polícia Pacificadora, que se instalaram em várias favelas, sobretudo naquelas localizadas nas áreas mais nobres da cidade ou nas artérias principais por onde passariam turistas e delegações para os Jogos olímpicos. Apesar do projeto anunciar a instalação de uma polícia comunitária, as práticas policiais nessas favelas foram rapidamente objeto de críticas diante da violência exacerbada e da corrupção generalizada da polícia (Gonçalves R.S., Amoroso M. e Brum M., 2014).

9 As manifestações de junho de 2013, que tinham como mote principal o aumento das passagens de ônibus, rapidamente se tornaram, no caso do Rio de Janeiro, numa dura crítica aos investimentos para os grandes eventos (Freire L., 2016). Um dos slogans proclamados nas ruas cariocas era: "não vai ter copa." Aqui, cabe uma crítica do 
afastamento de grande parte das forças progressistas das bases populares. O futebol é um elemento central do cotidiano brasileiro. A crítica de grupos de esquerda à organização dos grandes eventos esportivos se configurou também em uma chamada de boicote à Copa do Mundo e à própria seleção nacional. Enquanto isso, as manifestações de direita, que sucederam à reeleição de Dilma Rousseff para o seu impeachment, apropriaram-se das cores nacionais e sobretudo do uniforme da seleção canarinho.

No entanto, as críticas mais contundentes vieram da corrupção generalizada -chefiada pelo Movimento Democrático Brasileiro (MDB, ex PMDB) no Estado. Toda a cúpula do governo Sérgio Cabral (2007-2014) está presa, inclusive o próprio ex-governador, assim como o seu vice e sucessor, o também ex-governador Pezão (2014-2018). Esses casos de corrupção respingaram sobre o Partido dos trabalhadores (PT), já que o partido fazia parte da base política do MDB no Estado do Rio de Janeiro.

11 Além dos casos de corrupção, o Estado do Rio de Janeiro entrou em uma das piores crises de sua história. A corrupção generalizada, os pesados investimentos para preparar a cidade para os jogos olímpicos e a queda brutal do preço internacional do petróleo fizeram que o Estado entrasse em colapso financeiro, já em 2016. O Estado não tinha como honrar seus compromissos com fornecedores e ficou meses sem pagar o funcionalismo público. Após ter conseguido firmar, em janeiro de 2017, um acordo draconiano com o Governo federal de Michel Temer, que lhe permitiu, sob forte austeridade orçamentária, uma moratória da dívida junto ao governo federal, o governo Pezão conseguiu honrar seus compromissos, mas sem recursos para novos investimentos.

\section{0 contexto político fluminense}

12 Compreender a fragilidade política do campo político fluminense é importante para entendermos a eleição de Witzel. Essa eleição foi certamente a mais surpreendente desde a eleição de Leonel Brizola em 1982. Político de expressão nacional, exilado político e herdeiro do trabalhismo, Brizola era nacionalmente conhecido e tinha feito sua carreira política, antes do golpe militar de 1964, no Estado do Rio Grande do Sul. Eleito em 1982 e reeleito em 1990, monopolizou a política do Rio de Janeiro até os anos 2000 (SentoSé J.T., 2002). Grande parte dos políticos eleitos na cidade ou no Estado vieram de seu círculo político, mesmo que alguns já tivessem rompido com Brizola quando eleitos. Partidos nacionalmente tradicionais, como o PT ou o PSDB, nunca tiveram uma capilaridade política no Estado.

13 A luz vermelha no cenário político fluminense se acendeu com a eleição do bispo licenciado e até então senador da República, Marcelo Crivella. O seu nome sempre foi atrelado à Igreja Universal, sobretudo pelo fato de ter relações familiares com o fundador da Igreja, o bispo Edir Macedo. Sempre alcançava votações expressivas, mas jamais tinha conseguido sucesso em eleições majoritárias, já que a rejeição ao seu nome também era enorme. $\mathrm{O}$ forte discurso antipetista, que respingou também nos demais partidos de esquerda de forma genérica, permitiu a eleição de Marcelo Crivella contra Marcelo Freixo do PSOL nas eleições municipais de 2016. Ali ficava claro que grande parte do eleitorado estava disposta a apoiar qualquer candidato que pudesse barrar a esquerda.

14 Mesmo sendo considerado provavelmente como uma das piores gestões municipais da história recente do Rio de Janeiro (Cerqueira S. e Pereira Guimarães S., Veja Rio, 2018), o fracasso da gestão Crivella pouco influenciou as eleições de 2018. Witzel conseguiu o 
apoio maciço do mundo evangélico após a cassação da candidatura do ex-governador Anthony Garotinho, no dia 27 de setembro (Albuquerque A.L., Casado L. e Nogueira I., Folha de S. Paulo, 2018). Garotinho foi governador do Estado, vem da cidade de Campos, no Norte do Estado, e é fortemente ligado ao mundo evangélico. Condenado em segunda instância por formação de quadrilha (Altino L., O Globo, 2018), a sua candidatura foi cassada, o que permitiu à candidatura Witzel angariar grande parte do apoio evangélico ${ }^{4}$. Além dos evangélicos, recebeu forte apoio de grupos tradicionalistas da Igreja Católica Romana.

15 Grande parte de sua campanha foi constituída na destruição da herança do PMDB, com forte crítica aos inúmeros casos de corrupção e ao aumento da violência urbana. Mesmo que o outro candidato do segundo turno, o ex-prefeito Eduardo Paes, tenha saído do PMDB e se candidatou pelo DEM, o seu nome continua muito atrelado ao nome do exgovernador Cabral, já que foi prefeito da cidade (2009-2016) durante a preparação para os eventos internacionais.

\section{A pauta da segurança pública}

Dentre as diferentes pautas levantadas por Witzel, a questão da violência urbana mereceu uma atenção especial. A segurança pública é um problema público (Gusfield J., 1981) no Rio de Janeiro e ganha forte centralidade no debate político, sobretudo associado às favelas do Estado. Segundo o plano de governo de Witzel: "Sem falar no pior dos problemas do Rio de Janeiro: a segurança pública (...). Os índices de criminalidade explodiram. O cidadão fluminense vive em constante medo"5. Quando questionado durante a campanha se já esteve na favela da Rocinha, o então candidato Witzel respondeu: "Passei perto da Rocinha, nunca subi. Mas a gente não precisa subir para saber que lá realmente é ruim" (Filipe D., Publico, 2018). Witzel reforça a ideia da favela como epicentro da violência, e retoma a metáfora da guerra (Leite M.P., 2012) para tratar a questão da violência urbana.

O seu discurso sobre a segurança pública replicou em grande parte as propostas anunciadas por Bolsonaro em escala nacional. Uma primeira proposta polêmica do atual governador foi o "abate" de criminosos, portando fuzis em favelas (Magalhães L.E. e Altino L., O Globo, 2018). Para isso, quer treinar snipers, que poderão usar helicópteros ( G1 Rio, 30 Outubro 2018). Não se manifesta, entretanto, sobre o fato de que a polícia do Rio de Janeiro já é uma das mais letais do mundo, com muitos casos de mortes de moradores sem nenhuma relação com o narcotráfico. Witzel não traz nada de novo nas práticas policiais, só defende uma melhor formação militar com a criação de células de elite de combate ao crime em cada batalhão.

18 O seu objetivo é "chegar em 2022 com uma taxa de homicídios por 100 mil habitantes abaixo de dois dígitos e diminuir roubo de cargas a estabelecimentos comerciais e latrocínios" (Filipe D., Publico, 2018). Defende, assim, a compra de equipamentos de segurança, como sistema de reconhecimento facial, uso de drones e ampliação de câmaras de segurança na cidade (G1 Rio, 24 Outubro 2018). Afirmou, ainda, que pretende, junto com o senador Flávio Bolsonaro (PSL), viajar até Israel para "conhecer um modelo de drone equipado com uma arma, capaz de atirar enquanto sobrevoa uma região" (Filipe D., Publico, 2018). Suas propostas preveem, ainda, a realização de parcerias público-privadas para a construção de presídios e gestão dos atuais e a criação de uma Universidade da 
Polícia para um melhor treinamento dos policiais. Prevê, também, a possibilidade de realização de convênios com as prefeituras municipais, que quiserem armar suas Guardas Municipais em suas respectivas localidades, aumentando o contingente armado do policiamento ostensivo no Estado.

Outra decisão polêmica foi a extinção da Secretaria de Segurança Pública, constituindo um Gabinete de Segurança Pública, como órgão executivo do Estado, composto apenas pelo Governador, pelo Chefe da Polícia Civil e pelo Comandante Geral da Polícia Militar, os últimos com status de Secretário ${ }^{6}$. A justificativa dessa decisão é que as polícias precisam readquirir a autonomia de ação sem pressões políticas, ou seja, a questão da segurança pública perde seu caráter político e social para se resumir a uma questão policial strictu sensu.

Apesar do tom extremamente negativo em relação às favelas, o seu projeto de governo defende o fim das remoções e propõe um projeto de urbanização de favelas, nomeado Comunidade Cidade. Parte dessas intervenções estão também profundamente permeadas pela questão securitária, conforme demonstra um dos objetivos do plano habitacional do Estado: "garantir que as comunidades tenham infraestrutura viária que possam facilitar a ação policial" (G1 Rio, 24 Outubro 2018). Além das favelas, o discurso securitário abrange várias dimensões de sua agenda política como transformar algumas escolas públicas em escolas dirigidas diretamente pela polícia militar, alcançando ao menos uma escola por município no Estado ${ }^{7}$.

O contexto de crise política e econômica do Rio de Janeiro, como abordado, permitiu o sucesso eleitoral da extrema-direita, que se apropriou da questão da Segurança Pública. A centralidade dessa questão, para concluir, revela uma ausência de políticas concretas, seja à esquerda ou à direita, na democratização das forças de ordem pós-ditadura militar, assim como na formulação de políticas concretas à questão da violência urbana. As políticas que se desenham atualmente não se manifestam como uma novidade, mas reproduzem práticas repressivas, voltadas, mais uma vez, para a criminalização da pobreza.

\section{BIBLIOGRAFIA}

Albuquerque, Ana Luiza, Casado, Letícia e Nogueira, Italo, « TSE barra candidatura de Garotinho ao governo do Rio », Folha de S. Paulo [artigo online], 27/09/2018. URL : https:// www1.folha.uol.com.br/poder/2018/09/tse-barra-candidatura-de-garotinho-ao-governo-dorio.shtml

Altino, Lucas, « Garotinho é condenado em segunda instância por formação de quadrilha », 0 Globo [artigo online], 04/09/2018. URL : https://oglobo.globo.com/brasil/garotinho-condenadoem-segunda-instancia-por-formacao-de-quadrilha-23039610

Cerqueira Sofia e Pereira Guimarães Saulo, « Marcelo Crivella tem maior índice de rejeição na prefeitura em 25 anos », Veja Rio [artigo online], 15/06/2018. URL : https://vejario.abril.com.br/ cidades/marcelo-crivella-indice-de-rejeicao-prefeitura/ 
Filipe, Daniela, « Novo governador do Rio nunca foi à Rocinha e diz que não precisa de a conhecer » Publico [artigo online], 05/11/2018. URL : https://www.publico.pt/2018/11/05/ mundo/noticia/governador-eleito-rio-janeiro-quer-transformar-rocinha-bairro-matarcriminosos-arma-mao-1850004

Freire, Leticia Luna, « "Les Jeux Olympiques pour qui ?" Les actions du Comité Populaire de la Coupe du monde et des Jeux Olympiques de Rio de Janeiro contre un modèle urbain d'exclusion ", Problèmes d'Amérique latine, $\mathrm{v}^{\mathrm{0}}$ 4, nº 103, 2016, p.95-117.

G1 Rio, « Wilson Witzel: as promessas do candidato do PSC ao governo do RJ », G1 Rio [artigo online], 24/10/2018, URL : https://g1.globo.com/rj/rio-de-janeiro/eleicoes/2018/ noticia/2018/10/24/wilson-witzel-as-promessas-do-candidato-do-psc-ao-governo-do-rj.ghtml

Gonçalves, Rafael Soares, « Des Expositions aux Jeux Olympiques : Grands événements internationaux et interventions urbaines à Rio de Janeiro dans une perspective historique ", Problèmes d'Amérique latine, no103, v. 4, 2016, p.37-55.

Gonçalves, Rafael Soares, Amoroso, Mauro e Brum, Mário, « Police, participation et accès aux droits dans des favelas de Rio de Janeiro : l'expérience des Unités de police de pacification (UPP) », Revue ORDA - L’Ordinaire des Amériques, v. 216, 2014, p. 1-25.

Gusfield, Joseph, The culture of public problems: drinking-driving and the symbolic order, Chicago, University of Chicago Press, 1981.

Leite, Márcia Pereira, « Da "metáfora da guerra" ao projeto de "pacificação": favelas e políticas de segurança pública no Rio de Janeiro ", Revista brasileira de Segurança Pública, № 6, no 2, 2012, p.374-389.

Magalhães, Alexandre, "O "legado" dos megaeventos esportivos: a reatualização da remoção de favelas no Rio de Janeiro », Horizontes antropológicos, № 19, no 40, 2013, p.89-119.

Magalhães, Luiz Ernesto e Altino, Lucas, « Witzel quer usar snipers para abater criminosos com fuzis em favelas », O Globo [artigo online], 30/10/2018. URL : https://oglobo.globo.com/rio/ witzel-quer-usar-snipers-para-abater-criminosos-com-fuzis-em-favelas-23199100

Martins, Marco Antônio, « Conselheiro de Wilson Witzel explica como se formarão turmas de atiradores ", G1 Rio [artigo online], 02/11/2018. URL : https://g1.globo.com/rj/rio-de-janeiro/ noticia/2018/11/02/conselheiro-de-wilson-witzel-sobre-atiradores-explica-como-se-formaraoturmas-de-atiradores.ghtml

Mascarenhas, Gilmar, « A produção da cidade olímpica e os sinais da crise do modelo globalitário ", Geousp - Espaço e Tempo, № 20, oํ 1, 2016, p. 52-68.

Mendes, Alexandre F. e Legroux, Jean, « BRT Transoeste: conflitos urbanos e contradições espaciais na "cidade atrativa" ", Revista Direito e Praxis, № 7, no 4, 2016, p. 13-42.

Motta, Marly Silva da, « O Rio de Janeiro continua sendo ? », Rio de Janeiro, CPDOC, 2000.

O Globo, «É \#FATO que deputados eleitos pelo PSL quebraram placa com nome de Marielle Franco em comício de Wilson Witzel », G1 - O Globo [artigo online], 08/10/2018. URL : https:// g1.globo.com/fato-ou-fake/noticia/2018/10/08/e-fato-que-deputados-eleitos-pelo-pslquebraram-placa-com-nome-de-marielle-franco-em-comicio-de-wilson-witzel.ghtml

Sento-Sé, João Trajano, « O discurso brizolista e a cultura política carioca », Varia História, № 28, 2002, p.85-104.

Silva, Mauro Osorio e Versiani, Maria Helena, « História de capitalidade do Rio de Janeiro », Cadernos do Desenvolvimento Fluminense, no 10, 2016, p. 66-78. 
Vale, Josiane do e Gonçalves, Rafael Soares, «Intervención urbana y megaeventos en Río de Janeiro: resistencia de Vila Autódromo a la política de remoción », Limaq, n. ${ }^{\circ}$ 4, 2018, p. 123-141.

\section{NOTAS}

1. Um caso notório foi o comício realizado na cidade de Petrópolis junto com os candidatos do PSL a deputado (Daniel Silveira e Rodrigo Amorim), em que esses quebraram uma placa imitando as placas de rua do Rio de Janeiro com o nome da vereadora assassinada no início de 2018, Marielle Franco. Apesar de ressaltar que não sabia da decisão dos candidatos de destruírem a placa, essa imagem foi amplamente divulgada e reforçou o discurso extremista do então candidato Wilson Witzel. Ver: «É \#FATO que deputados eleitos pelo PSL quebraram placa com nome de Marielle Franco em comício de Wilson Witzel », G1 - O Globo [artigo online], 08/10/2018.

2. O PSC é formado basicamente por evangélicos e grupos conservadores da Igreja Católica Romana. Apresenta uma retórica anticomunista e defende medidas liberais na economia e valores tradicionalistas no âmbito moral.

3. Sobre o fato da cidade do Rio de Janeiro continuar exercendo o papel de cidade-capital do país mesmo sem ser mais a capital política nem a econômica, ver os artigos de Marly Motta da Silva (2000) e Mauro Osório da Silva e Maria Helena Versiani (2016).

4. Garotinho é um dos grandes articuladores do Governo Witzel junto à Assembleia Legislativa e parece ter aderido abertamente ao novo governo.

5. Plano de Governo de Wilson Witzel (PSC), 2018, p. 4 [online]. URL: http:// divulgacandcontas.tse.jus.br/candidaturas/oficial/2018/BR/RJ/2022802018/190000612301/

proposta_1534218285632.pdf, acessado em janeiro de 2019.

6. Ibid., p. 4.

7. Ibid., p. 41 .

\section{AUTOR}

\section{RAFAEL SOARES GONÇALVES}

Advogado e historiador. Doutor em História e Civilização pela Universidade de Paris VII. Pósdoutor em Antropologia pela EHESS. Professor associado do Departamento de Serviço Social da PUC-Rio. Pesquisador CNPQ e FAPERJ. Coordenador do Laboratório de Estudos Urbanos e Socioambientais (LEUS) e editor científico da revista 0 social em Questão. 